\title{
Study of selective immunoglobulin A deficiency among Egyptian patients with food allergy
}

\author{
RASHA YOUSSEF SHAHIN ${ }^{I}$, FAWZIA HASSAN ABO ALI ${ }^{1}$, NERMINE ABDEL NOUR MELEK', \\ ISLAM ADEL ABD ELATEEF ${ }^{2}$, MOHAMED YOUSSEF ATTIA ${ }^{3}$ \\ ${ }^{1}$ Department of Internal Medicine, Allergy and Clinical Immunology, Faculty of Medicine, Ain Shams University, Cairo, Egypt \\ ${ }^{2}$ Faculty of Medicine, Ain Shams University, Cairo, Egypt \\ ${ }^{3}$ Immunology Laboratory, Ain Shams University Hospital, Cairo, Egypt
}

\begin{abstract}
Introduction: IgA deficiency is one of the commonest primary antibody deficiencies. Although many affected individuals could be asymptomatic, selected patients suffer from recurrent mucosal infections, allergies, and autoimmune diseases.

Aim of the study: To investigate the prevalence of IgA deficiency among Egyptian patients with food allergy.

Material and methods: We studied 100 patients (62 males, 38 females; mean age, 28.6 years) with multiple food allergies who were recruited on the basis of adequate immunological assessment by history, skin prick test, and confirmed by open challenge test as well as 50 healthy controls. Measurement of levels of IgE and IgA using ELISA technique were performed for all patients and controls.

Results: Deficiency of IgA was detected in $67 \%$ of patients with food allergy. Serum IgA levels were significantly lower among patients with food allergy $(67.3 \mu \mathrm{g} / \mathrm{ml}$; range, 56.7-72.0 $\mu \mathrm{g} / \mathrm{ml})$ as compared to healthy control (78.6 $\mu \mathrm{g} / \mathrm{ml}$; range, $72.8-84 \mu \mathrm{g} / \mathrm{ml})$. Both IgA and IgE levels were not statistically different between patients with food allergy only and those with combined food and aeroallergen. Among food allergic group, serum IgA levels were inversely correlated with serum IgE levels $(r=-0.314$, $p<0.001)$.

Conclusions: Manifestations of atopy, such as food allergy might be a present feature before diag-
\end{abstract} nosis of primary immune deficiency diseases as IgA deficiency.

Key words: food allergy, immunoglobulin E, immunoglobulin A, immunodeficiency, selective IgA deficiency.

(Cent Eur J Immunol 2020; 45 (2): 184-188)

\section{Introduction}

Immunoglobulin $\mathrm{E}$ ( $\mathrm{IgE})$ is considered the main component of type 1 hypersensitivity reaction [1] that clinically presents with anaphylaxis, asthma, atopic dermatitis, and allergic rhinitis [2, 3]. IgE-mediated food allergy is a common disease especially in children, with high-risk of potentially life-threatening anaphylactic reactions. A better understanding of the disease and active investigation for efficient prevention or treatment is required and important [4].

Primary immunodeficiency diseases (PIDDs) that usually result from inherent defects in the immune system, appear mainly with recurrent or severe infections but also, they may involve autoimmune disease, lymphoproliferation, or allergy [5]. Allergic diseases are an important expression of misdirected immunity, and certain PIDDs are frequently associated with atopy. Selective $\operatorname{IgA}$ deficiency (sIgAD) is associated with atopy, e.g. asthma, allergic rhinitis, atopic dermatitis, and food allergy [6]. And nearly $25 \%$ of patients with IgA deficiency are identified during evaluation for allergic disorders [7]. However, about 85$90 \%$ of patients with IgA deficiency are asymptomatic [8].

Secretory IgA plays an important role in the immune homeostasis of gut, as it provides first line defense through the aggregation, immobilization, and neutralization of pathogenic microbes and harmful molecules, which interact with mucosal surfaces [9]. Food proteins are one of the molecules that reach human mucosal tissues. Defective antigen elimination, because of dysregulation of the immune response in IgA deficient individuals, might be considered as a risk factor accompanying development of food allergy [10]. 
Indeed, many cross-sectional studies have shown a higher prevalence of atopic conditions either in patients with SIgAD [11] or common variable immunodeficiency, suggesting a potential association [12]. However, there are little definitive data in the literature on the overall prevalence of food allergies as a specific expression of clinically relevant atopy in patients with asymptomatic sIgAD. For this purpose, this work presents one of a few broad considerations of the prevalence of SIgAD among patients with food allergy.

\section{Material and methods}

This prospective case control study with analysis of clinical and immunologic characteristic of patients with food allergy referred to allergy and immunology outpatient clinic, Ain Shams University Hospital, which is one of the referral tertiary medical center in Cairo, Egypt. One hundred patients were recruited from January 2015 to March 2016. None of them reported recurrent episodes of respiratory tract infections. Patients with associated autoimmune diseases were excluded. Fifty healthy volunteers were selected as the control group.

Patients were suspected for diagnosis of food allergy based on a history of significant skin, digestive, or respiratory reaction related to exposure to any potential food allergen. Furthermore, foods suspected based on the history and skin prick test were completely excluded from the diet. Resolution of symptoms on elimination of offending foods and recurrence of symptoms by open food challenge test was suggestive of food allergy.

The allergy status of patients was evaluated by skin prick test on the forearm, using common standard allergen extracts (Stallergen, France), such as cow's milk, wheat, soya, peanut, nuts, egg, fish, fruits, and other environmental antigens. Histamine and normal saline were simultaneously used as positive and negative controls, respectively. A wheal formation $\geq 3 \mathrm{~mm}$ above negative control after 15-20 min was considered as positive.

The study protocol was approved by the local research ethics committee of Ain Shams University, and informed consent was obtained from every participant included into the study.
Diagnosis of sIgAD was based on low or absent serum IgA level less than $0.07 \mathrm{~g} / \mathrm{l}(<70 \mu \mathrm{g} / \mathrm{ml})$, and normal IgG and IgM levels in patients older than 4 years old [13]. Concentrations of IgA in plasma were measured by ELISA (Assaypro LLC, St. Charles, USA). A polyclonal antibody specific for human IgA was pre-coated on a 96-well microplate with removable strips. IgA in standards and samples was sandwiched by immobilized antibody and biotinylated polyclonal antibody specific for IgA, which were recognized by a streptavidin-peroxidase conjugate. All unbound material was washed away, and a peroxidase enzyme substrate was added. The color development was interrupted, and the intensity of color was measured. Normal serum IgA levels were $70-400 \mu \mathrm{g} / \mathrm{ml}$.

Total IgE level was determined using Immuno CAP system (Pharmacia AB Diagnostics, Uppsala, Sweden), and the test was defined as positive for a value $>100 \mathrm{IU} / \mathrm{ml}$.

\section{Statistical analysis}

Data analysis was performed by SPSS statistical software package, version 22 (SPSS Inc., Armonk, NY, USA). Data were expressed as mean \pm standard deviation (SD) for parametric data, and as median and interquartile range (IQR) for non-parametric data. Parametric data were analyzed using Student's $t$-test while non-parametric data were evaluated with Mann-Whitney $U$ test to compare two groups. $\chi^{2}$ test was applied to compare categorical data, and Spearman's correlation coefficient was performed to assess the strength of the relationship between serum IgA levels and different quantitative parameters. The statistical significance level was set as $p=0.05$.

\section{Results}

One hundred patients with food allergy (62 males, 38 females), aged $28.6 \pm 7.4$ years, were evaluated. Of the 50 healthy control, $74 \%$ were males, and their mean age was 30.1 years. The total serum IgE levels compared to control group was higher in $75(75 \%)$ patients with food allergy. Characteristics of the study subjects are summarized in Table 1.

The most prevalent presentations of food allergy were urticaria/rash/eczema occurring in sixty-one sub-

Table 1. Characteristic of the study groups

\begin{tabular}{|c|c|c|c|}
\hline Parameter & $\begin{array}{l}\text { Food allergic group } \\
\qquad(n=100)\end{array}$ & $\begin{array}{l}\text { Control group } \\
\quad(n=\mathbf{5 0})\end{array}$ & $p$-value \\
\hline Age (years), mean $\pm \mathrm{SD}$ & $28.6 \pm 7.4$ & $30.1 \pm 7.0$ & 0.227 \\
\hline Gender, $n(\%)$ & & & 0.200 \\
\hline Male & $62(62)$ & $37(74)$ & \\
\hline Female & $38(38)$ & $13(26)$ & \\
\hline Total serum IgE (IU/ml), median (IQR) & $161.4(96-305)$ & $79.5(67.8-89)$ & $<0.001^{*}$ \\
\hline
\end{tabular}




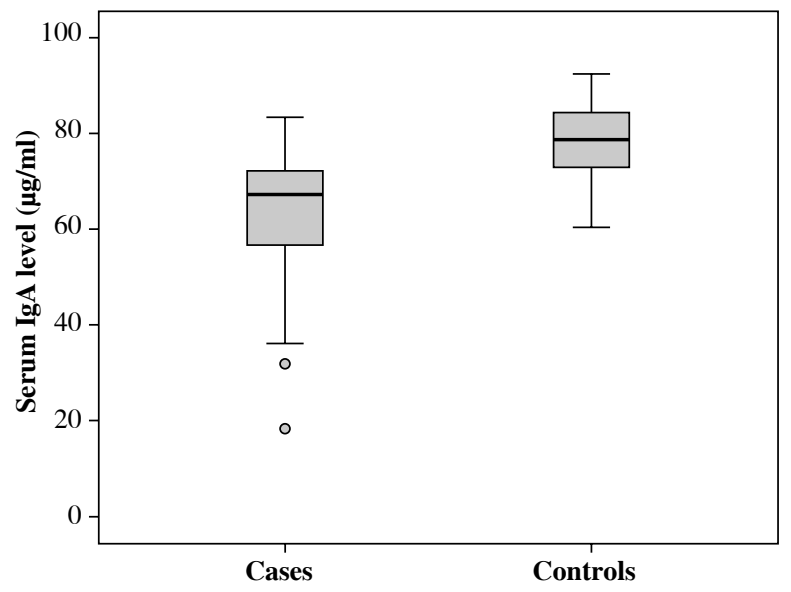

Fig. 1. Serum IgA levels among cases with food allergy and controls. Values given are the median and interquartile range of serum $\operatorname{IgA}$

jects $(61 \%)$, followed by asthma in thirty-six cases $(36 \%)$, gastrointestinal manifestations (diarrhea or vomiting) in twenty-eight patients (28\%), and hay fever in twenty-four (24\%) cases.

Skin prick tests for milk, wheat, egg, fruits, and nuts were predictive in almost all cases with positive reactions. IgA tended to low-normal range or below, and 67\% of patients had serum IgA $<70 \mu \mathrm{g} / \mathrm{ml}$. The median IgA in patients with food allergy was $67.3 \mu \mathrm{g} / \mathrm{ml}$, and in the control group it was $78.6 \mu \mathrm{g} / \mathrm{ml}$ with only $2 \%$ diagnosed as cases of IgA deficiency (OR, 23.3; 95\% CI: 8.1-66.06; $p<0.001$ ) (Fig. 1).

Furthermore, of 67 (67\%) food allergic patients with asymptomatic IgA deficiency, only 53 (70.7\%) demonstrated high levels of serum total IgE. As shown in Figure 2 , serum total $\operatorname{IgE}$ among food allergic patients correlated significantly with serum IgA levels $(r=-0.314, p=0.001)$.

According to skin prick results, patients were further classified into two groups: group with pure food allergy

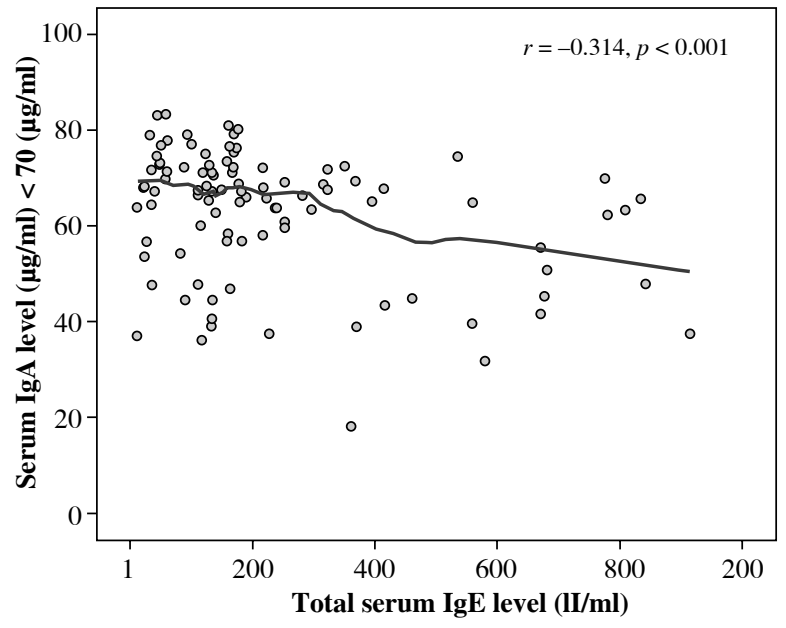

Fig. 2. Correlation between serum IgA and total serum IgE levels among food allergic patients (normal serum IgA $<70 \mu \mathrm{g} / \mathrm{ml})$

and another group with combined food and aeroallergens. However, we did not detect any difference in levels of serum IgA between either of the two groups (OR, 1.41; 95\% CI: 0.6-3.24; $p=0.430$ ) (Table 2, Fig. 3).

\section{Discussion}

Antibody production defects may be associated with health problems beyond just recurrent infection due to hypogammaglobulinemia but present an increased risk of allergy to alimentary antigens.

IgA deficiency prevalence is variable as most of cases are asymptomatic, and there is no established routine screening program for assessing $\operatorname{Ig}$ A deficiency [7].

It has been suggested that $25 \%$ of patients with $\operatorname{IgA}$ deficiency could be identified during an allergy evaluation [7]. It is worth to mention that the prevalence of selective IgA deficiency among adult patients with food allergy in the current study was $67 \%$, and the median of serum IgA was

Table 2. Serum total IgE, serum IgA, and other parameters among cases with food allergy and cases with combined food and aeroallergens

\begin{tabular}{lccc}
\hline Parameter & $\begin{array}{c}\text { Food allergic cases } \\
(\boldsymbol{n}=\mathbf{4 5})\end{array}$ & $\begin{array}{c}\text { Combined food and aeroallergen } \\
(\boldsymbol{n}=\mathbf{5 5})\end{array}$ & $\boldsymbol{p}$-value \\
\hline Age (years), mean \pm SD & $30.4 \pm 6.7$ & $27.4 \pm 7.7$ & 0.072 \\
\hline Gender, $n(\%)$ & & 0.836 & \\
\hline Male & $17(37.7)$ & $20(36.4)$ & \\
\hline Female & $28(62.2)$ & $35(63.6)$ & 0.495 \\
\hline Total serum IgE $(\mathrm{IU} / \mathrm{ml})$, median $(\mathrm{IQR})$ & $160.8(114.7-309.1)$ & $162(82.8-295.5)$ & 0.554 \\
\hline Serum IgA level $(\mu \mathrm{g} / \mathrm{ml})$, median $(\mathrm{IQR})$ & $65.6(47.7,71.3)$ & $67.4(57,72)$ & \\
\hline
\end{tabular}

IgE-immunoglobulin E, IgA - immunoglobulin A, IQR - interquartile range, $S D$ - standard deviation 
$67.3 \mu \mathrm{g} / \mathrm{ml}$. This findings is consistent to those of Latcham et al., who reported that IgA tended to be at the low-normal range or below in food allergic patients $(0.6 \mathrm{~g} / \mathrm{l})$, and $45 \%$ of children had IgA level below $0.3 \mathrm{~g} / 1$ [14].

In a Korean study evaluating the relationships between serum IgA and allergic diseases in Korean children [15], serum values of $\mathrm{IgA}$ were much lower, with $31.1 \mathrm{mg} / \mathrm{ml}$ (range, $14.3-50.6 \mathrm{mg} / \mathrm{ml}$ ) in cases of food allergy. This discrepancy may be attributed to the difference in age in the studied group and geographical distribution, as far Asian region has low prevalence $(1 / 31,800)$, which may suggest a genetic influence on the development of IgA deficiency [16].

Most previous studies assessed the prevalence of different atopic conditions among patients with SIgAD. In 1987, in his epidemiological study on immunoglobulin A deficiency, Klemola described a possibility of concomitant occurrence of allergic diseases and hypogammaglobulinemia in children and reported symptoms of atopic diseases in $50 \%$ of children with SIgAD [17]. This is practically similar to findings from a study by Szczawińska-Popłonyk et al. on food allergy in children with hypogammaglobulinemia indicating nearly $74 \%$ of children with symptoms of atopic diseases [10]. Despite low number of patients in a study performed by a research consortium known as the US Immunodeficiency Network (USIDNET), food allergy was found in $25 \%$ of those with SIgAD, which is similar to the results (30\%) of Aghamohammadi et al. in a prospective cohort of Iranian patients with sIgAD and self-reported food allergy [18].

These above-mentioned findings are consistent with the current knowledge on mucosal secretory $\operatorname{IgA}$ involvement in the gut epithelial barrier function and immunological homeostasis, including antibody-mediated immune exclusion of microbial components [19] and tolerance mechanisms to foods [20]. Additionally, it has been demonstrated that both serum antigen-specific IgA and IgG antibodies possibly play an important role in protection against severe IgE-mediated food allergy. Therefore, the decrease of serum neutralizing IgG and IgA antibody levels that occurs in patients with hypogammaglobulinemia may predispose to increased intestinal mucosal permeability and subsequently, systemic absorption of ingested antigens, thus posing the risk of severe food allergy [10].

Moreover, an atopic patient might be at high-risk of systemic IgE-mediated reactions to alimentary allergens and in our study group, increased levels of serum total IgE were demonstrated in $70.7 \%$ patients with food allergy, in whom asymptomatic selective IgA deficiency was accidently discovered. This is consistent with a study by Tuano et al., who assumed that patients with sIgA deficiency have a higher incidence of pure IgE-mediated rather than mixed or non-IgE-mediated manifestations of disease [21]. However, in a Turkish study, serum IgE level increased by $37.3 \%$ in patients with IgA deficiency. On the contrary, in a Polish study on children with hypogammaglobulinemia,

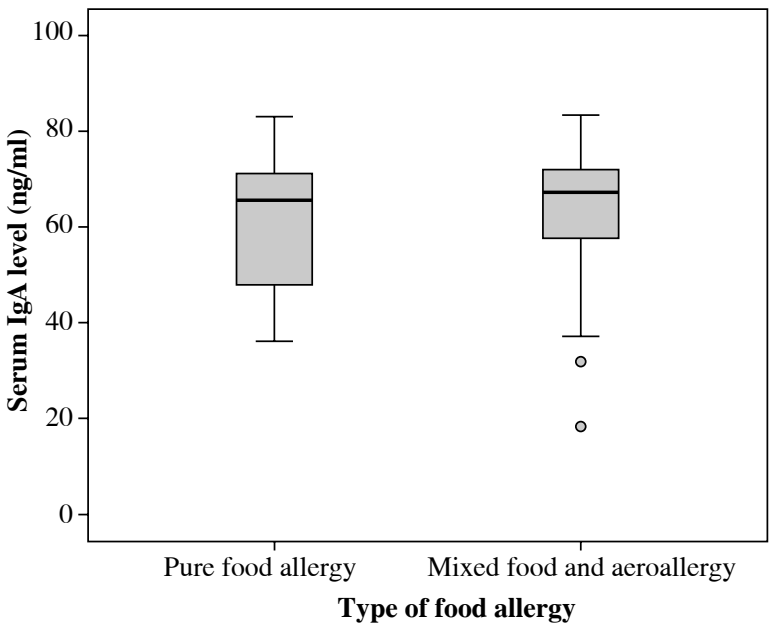

Fig. 3. Serum IgA levels among cases with food allergy alone and patients with combined food allergy and aeroallergen. Values given are the median and interquartile range of serum $\operatorname{IgA}$

atopy in form of increased levels of serum total $\operatorname{IgE}$ was revealed in 8 of 17 children (47\%) with food allergy [10]. Also, in another study by Dorsay and Orange, who retrospectively reviewed a group of 24 children with transient hypogammaglobulinemia of infancy, despite elevated levels of IgE in only 7 patients, twenty patients carried at least one atopic disorder [22]. These above-mentioned findings are supported by other authors' opinions that patients with hypogammaglobulinemia and concomitant allergic diseases may demonstrate poor correlation between clinical symptoms and results of either serum total or allergen specific IgE tests. Therefore, serum IgE levels cannot be considered as suitable diagnostic criteria for allergic disease in patients with defective antibody synthesis [23].

Furthermore, in the present study, food allergic patients were classified into two groups based on existence or absence of concomitant aeroallergen. However, no difference in the deficient state of IgA was associated with either food allergy alone, or in combination with aeroallergen sensitization.

\section{Conclusions}

In conclusion, measurement of serum IgA should not be considered only in patients with recurrent infections but also should be suspected in cases of allergic and autoimmune diseases. Food allergic sensitization are associated with an increased prevalence of low-normal concentrations of plasma IgA. Dysregulation of the immune response contributing to defect in antigen elimination in predisposed immunodeficient individuals might be considered as a critical risk factor accompanying development of allergy.

The authors declare no conflict of interest. 


\section{References}

1. Gould HJ, Ramadani F (2015): IgE responses in mouse and man and the persistence of IgE memory. Trends Immunol 36: 40-48.

2. Dullaers M, de Bruyne R, Ramadani F, et al. (2012): The who, where, and when of IgE in allergic airway disease. J Allergy Clin Immunol 129: 635-645.

3. Batchelor JM, Grindlay DJC, Williams HC (2010): What's new in atopic eczema? An analysis of systematic reviews published in 2008 and 2009. Clin Exp Dermatol 35: 823-827.

4. Frossard CP, Hauser C, Eigenmann PA (2004): Antigen-specific secretory IgA antibodies in the gut are decreased in a mouse model of food allergy. J Allergy Clin Immunol 114: 377-382.

5. Notarangelo LD (2010): Primary immunodeficiencies. J Allergy Clin Immunol 125 (Suppl 2): S182-194.

6. Janzi M, Kull I, Sjöberg R, et al. (2009): Selective IgA deficiency in early life: Association to infections and allergic diseases during childhood. Clin Immunol 133: 78-85.

7. Cunningham-Rundles C (2001): Physiology of IgA and IgA deficiency. J Clin Immunol 21: 303-309.

8. Yel L (2010): Selective IgA deficiency. J Clin Immunol 30: 10-16.

9. Pabst $\mathrm{O}$ (2012): New concepts in the generation and functions of IgA. Nat Rev Immunol 12: 821-832.

10. Szczawinska-Poplonyk A, Bręborowicz A, Ossowska L (2012): Food allergy in children with hypogammaglobulinemia. Pediatr Pol 87: 444-448.

11. Edwards E, Razvi S, Cunningham-Rundles C (2004): IgA deficiency: clinical correlates and responses to pneumococcal vaccine. Clin Immunol 111: 93-97.

12. Ogershok PR, Hogan MB, Welch JE, et al. (2006): Spectrum of illness in pediatric common variable immunodeficiency. Ann Allergy Asthma Immunol 97: 653-656.

13. Al-Herz W, Bousfiha A, Casanova J-L, et al. (2014): Cunningham-Rundles $\mathrm{C}$, et al. Primary immunodeficiency diseases: an update on the classification from the International Union of Immunological Societies Expert Committee for Primary Immunodeficiency. Front Immunol 5: 162.

14. Latcham F, Merino F, Lang A, et al. (2003): A consistent pattern of minor immunodeficiency and subtle enteropathy in children with multiple food allergy. J Pediatri 143: 39-47.

15. Park JS, Han YI, Han MY, et al. (2015): Relationships between serum immunoglobulin A levels and allergic diseases in Korean children. Allergy Asthma Respir Dis 3: 109-115.

16. Palmer DS, O'Toole J, Montreuil T, et al. Screening of Canadian Blood Services donors for severe immunoglobulin A deficiency. Transfusion 50: 1524-1531.

17. Klemola T (1987): Deficiency of immunoglobulin A. Ann Clin Res 19: 248-257.

18. Aghamohhammadi A, Cheraghi T, Gharagozlou M, et al. (2009): IgA deficiency: correlation between clinical and immunological phenotypes. J Clin Immunol 29: 130-136.

19. Karlsson MR, Johansen FE, Kahu H, et al. (2010): Hypersensitivity and oral tolerance in the absence of a secretory immune system. Allergy 65: 561-570.

20. Vickery BP, Chin S, Burks W (2011): Pathophysiology of food allergy. Pediatr Clin North Am 58: 363-376.

21. Tuano KS, Orange JS, Sullivan K, et al. (2015): Food allergy in patients with primary immunodeficiency diseases: Prevalence within the US Immunodeficiency Network (USIDNET). J Allergy Clin Immunol 135: 273-275.
22. Dorsey MJ, Orange JS (2006): Impaired specific antibody response and increased B-cell population in transient hypogammaglobulinemia of infancy. Ann Allergy Asthma Immunol 97: 590-595.

23. MacGinnitie A, Aloi F, Mishra S (2011): Clinical characteristics of pediatric patients evaluated for primary immunodeficiency. Pediatr Allergy Immunol 22: 671-675. 